\title{
Prevalence of cardiovascular risk factors in non-menopausal and postmenopausal inpatients with type 2 diabetes mellitus in China
}

Huanhuan Zhou, Chenghuan Zhang, Jingyu Ni and Xiaoyun Han * (D)

\begin{abstract}
Background: To investigate the prevalence of cardiovascular disease (CVD) risk factors and assess the 10-year risk of CVD in non-menopausal and postmenopausal women with type 2 diabetes mellitus (T2DM).

Methods: A total of 569 patients with T2DM at a Chinese tertiary hospital were investigated using the Framingham Risk Score (FRS). We evaluated the 10-year risk of CVD, clinical and menopause characteristics in all subjects.

Results: Among the 569 diabetic patients, the incidence of smoking, dyslipidemia, hypertension, overweight or obesity, and nonalcoholic fatty liver disease (NAFLD) was 0.7, 36.2, 38.156 .6 and 58.2\%, respectively. The usage rate of hypoglycemic agents, antihypertensive agents, lipid modulators and antithrombotic drugs was 88.6, 78.3, 50.0 and $27.1 \%$, respectively. However, only $1.2 \%$ of inpatients achieved the three target goals for the control of blood glucose $\left(\mathrm{HbA}_{1 c}<7 \%\right)$, blood pressure (systolic blood pressure $<130 \mathrm{mmHg}$, diastolic blood pressure $<80 \mathrm{mmHg}$ ), and blood lipids (total cholesterol $<174 \mathrm{mg} / \mathrm{dL}$ ). The 10-year risk of CVD was $(1.6 \pm 1.5 \%)$ and tended to increase along with age $(F=27.726, P<0.001)$. For all subjects $(n=569)$, multiple linear regression analysis showed that menopause $(\beta=0.275, P<0.001)$, low-density lipoprotein cholesterol (LDL-C) $(\beta=0.212, P<0.001)$, fasting plasma glucose (FPG) $(\beta=0.093, P=0.018)$ and waist-to-hip-ratio $(\beta=-0.078, P=0.047)$ were risk factors of 10-year risk of $C V D$, which may explain the variance of $14.3 \%$. In the postmenopausal group $(n=397), \operatorname{LDL}-C(\beta=0.227, P<0.001)$, $\operatorname{FPG}(\beta=0.139, P=0.003)$ and time since menopause $(\beta=0.230, P<0.001)$ were found to be associated with CVD, which may explain the variance of $14.6 \%$.

Conclusion: The incidence of dyslipidmia, hypertension, overweight or obesity and NAFLD is high. The level of control of blood glucose, blood pressure, and blood lipids was found to be extremely low and the treatment status was not ideal. Besides menopause, LDL-C, FPG and time since menopause were found to be independent risk factors for the 10-year risk of CVD. Therefore, it is necessary to focus on comprehensive control of multiple risk factors, such as plasma glucose, blood pressure and serum lipid.
\end{abstract}

Keywords: Diabetes mellitus, Type 2, Menopause, Cardiovascular disease, Framingham risk score

\footnotetext{
* Correspondence: lanao163@sina.com

The First People's Hospital of Changzhou, 185\# Juqian Road, Changzhou

213000, Jiangsu Province, China
}

(c) The Author(s). 2019 Open Access This article is distributed under the terms of the Creative Commons Attribution 4.0 International License (http://creativecommons.org/licenses/by/4.0/), which permits unrestricted use, distribution, and reproduction in any medium, provided you give appropriate credit to the original author(s) and the source, provide a link to the Creative Commons license, and indicate if changes were made. The Creative Commons Public Domain Dedication waiver (http://creativecommons.org/publicdomain/zero/1.0/) applies to the data made available in this article, unless otherwise stated. 


\section{Background}

Cardiovascular disease (CVD) is a leading cause of mortality and morbidity worldwide [1]. The prevalence of CVD in China has increased rapidly since 2010, with stroke and ischemic heart disease accounting for most deaths [2] and is the first cause of death in Chinese women. However, in previous studies, compared to nonmenopausal women, the incidence of CVD among postmenopausal women was found to be higher [3, 4]. The association between menopausal transition and the incidence of CVD is well known. For example, the increase in CVD risk is related to significant hormonal changes, especially estrogen deprivation at the time of menopause [4]. A decrease in oestradiol levels can lead to metabolic disorders, such as dyslipidemia, hypertension and increased central adiposity, which are considered to be cardiovascular risk factors [4-6].

As is well known, diabetes mellitus is a significant risk factor for developing CVD. The major pathological basis of CVD begins with endothelial damage or dysfunction $[7,8]$. A review has suggested that the female sex hormone estrogen mediates the relative protection of premenopausal women against cardiovascular disease, compared with agematched men [9]. However, these protective effects are absent in women with diabetes $[10,11]$. Among diabetic patients, high glucose promotes the increase of reactive oxygen species formation, which may neutralize the vasorelaxant and anti-inflammatory effects of NO [12]. In hyperglycemia, the estrogen receptors $\alpha$ to estrogen receptors $\beta$ ratio declined with the decreased secretion of estrogen modulation on endothelial estrogen receptor expression, which may lead to vascular injury [13]. Diabetes also changes the vascular tissue at the molecular level by enhancing oxidative stress and pro-inflammatory response, as well as advancing glycation end products and protein Kinase $\mathrm{C}$ activation, which together promote the development of CVD [14]. In addition, among menopausal patients, age at menopause, time since menopause, and total reproductive years (i.e., the duration between menarche and menopause) may determine the duration and level of exposure to endogenous estrogen $[15,16]$. Therefore, the risk of CVD among postmenopausal women with diabetics is higher. These findings are primarily based on studies conducted in Western populations. The relationship between the risk of CVD and menopause has been widely studied in China. Wu et al. [17] demonstrated that during a median follow-up period of 11.2 years, 246 out of 31,955 died from diabetes. In a Kailuan study, diabetic participants only accounted for $2.5 \%$ of all deaths [18]. A study by Gallagher et al. selected patients from among textile workers, but information on their diabetes status was not available [19]. These studies sampled the general population, but there is no research that has focused on diabetic patients in China [1, 17-19]. Therefore, the aim of the present study was to investigate the prevalence of CVD risk factors and assess the 10-year risk of CVD using the Framingham Risk Score (FRS) on 569 non-menopausal and postmenopausal women with type 2 diabetes mellitus in China.

\section{Methods \\ Participants}

This cross-sectional survey was performed at a tertiary hospital in Changzhou, Jiangsu Province, China, using a convenient sample size of 600 admission patients with type 2 diabetes mellitus between January 2016 and January 2018. The inclusion criteria were female patients aged 18 years or above, who were admitted to the Department of Endocrinology, and had type 2 diabetes mellitus for at least 3 months and were able to communicate fluently and clearly. Exclusion criteria were patients with type 1 diabetes mellitus, dementia or a severe illness, such as cancer or other immune system diseases, serious accompanied diseases or complications, psychosis, coronary heart disease, arrhythmia, stroke and those who were pregnant or lactating. After excluding 31 subjects with missing clinical characteristics, 569 out of the 600 eligible participants completed the surveys, representing a $95.5 \%$ response rate.

Patients who met the inclusion criteria and gave verbal informed consent were acquired to complete the surveys. The present study was approved by the Ethics Committee of the Hospital.

\section{Data collection}

The patients were required to undergo a series of examinations, including demographic and clinical characteristics and a biochemical evaluation for the analysis. The information included age, diabetes course, family history, history of present illness, height, body weight, blood pressure, smoking, alcohol intake habits and current medications. Blood chemistry values assessed included $\mathrm{HbA}_{1 \mathrm{c}}$, plasma glucose, C peptide levels, 4 items of blood lipid tests and apolipoprotein concentrations. Blood sampling was performed at a clinical testing center of our hospital. Two health care professionals who were trained as data collectors used uniform instructions to guarantee the quality of data collection. Two other data collectors obtained further information on age at menarche, menstrual days and cycle, menopause age, treatment regimens, hypoglycemia and complications, through face to face interviews. We classified the 569 patients into non-menopause $(n=172)$, postmenopause $<5$ y $(n=231)$ and postmenopause $\geq 5$ y $(n=166)$ based on whether they were menopausal or not and time since menopause.

Patients were identified as dyslipidemic, if any one of the following indexes were met: total cholesterol (TC) level $\geq 240 \mathrm{mg} / \mathrm{dL}$, low-density lipoprotein cholesterol 
(LDL-C) level $\geq 160 \mathrm{mg} / \mathrm{dL}$, triglycerides (TG) level $\geq 88$ $\mathrm{mg} / \mathrm{dL}$, high-density lipoprotein cholesterol (HDL-C) level $\leq 40 \mathrm{mg} / \mathrm{dL}$ or if the patients were taking lipidregulating drugs [20].

A diagnosis of hypertension was made in the absence of antihypertensive drugs, when systolic blood pressure $(\mathrm{SBP}) \geq 140 \mathrm{mmHg}$ and/or diastolic blood pressure (DBP) $\geq$ $90 \mathrm{mmHg}$; a previous history of hypertension, currently using antihypertensive drugs [21]. Weight was classified as follows: normal weight, BMI $<24 \mathrm{~kg} / \mathrm{m}^{2}$; overweight, BMI $24-27.9 \mathrm{~kg} / \mathrm{m}^{2}$; Obese, BMI $\geq 28 \mathrm{~kg} / \mathrm{m}^{2}$ [21].

A general check-up was performed by an internal medicine physician. Two independent radiologists interpreted the abdominal ultrasonography results of all patients at the time of the initial evaluation to determine the presence of NAFLD [22].

The target goals of blood glucose, blood pressure and blood lipids were $\mathrm{HbA}_{1 \mathrm{c}}<7 \%$, blood pressure $<$ $130 / 80 \mathrm{mmHg}$ and $\mathrm{TC}<174 \mathrm{mg} / \mathrm{dL}$, which are based on Guidelines for Diabetes Prevention and Treatment in China [21].

\section{Assessment of cardiovascular risk}

FRS was used to evaluate the 10-year risk of CVD [23]. Based on the gender of the subjects, female FRS scores were selected and calculated using five risk factors, including age, TC, HDL-C, SBP and smoking. The cutoff values for calculating FRS are as follows: age, 20-34 y, 7 points; $35-39$ y, -3 points; $40-44 \mathrm{y}, 0$ points; $45-49$ y, 3 points; 50-54 y, 6 points; $55-59$ y, 8 points; $60-64$ y, 10 points; $65-69 \mathrm{y}, 12$ points; 70-74 y, 14 points; 75-79 y, 16 points; TC level $<160,160-199,200-239,240-279$, and $\geq 280 \mathrm{mg} / \mathrm{dL}$; HDL-C level: <40, 40-49, 50-59, and $\geq 60 \mathrm{mg} / \mathrm{dL}$; SBP: $<120,120-129,130-139,140$ 159 , and $\geq 160 \mathrm{mmHg}$; nonsmoker or smoker [23]. The 10 year CVD risk percentage was calculated using the total number of points: $<9$ points, $<1 \%$; 9-12 points, $1 \%$; $13-14$ points, $2 \%$; 15 points, $3 \%$; 16 points, $4 \%$; 17 points, $5 \%$; 18 points, $6 \%$; 19 points, $8 \%$; 20 points, $11 \%$, 21 points, 14\%; 22 points, $17 \%$; 23 points, $22 \%$; 24 points, $27 \%$; 25 points or more $\geq 30 \%$. Absolute 10 year CVD risk percentage was classified as low risk, $<10 \%$; moderate risk, 10-20\%; and high risk, $>20 \%$ [23]. In the light of FRS, cardiovascular risk factors (age, TC, HDL-C, SBP and smoking) were assessed for all patients.

\section{Statistical analysis}

IBM SPSS ver. 22.0 (SPSS Inc., Chicago, IL, USA) was used to perform the statistical analysis. All data are expressed as mean \pm standard deviation or percentage, where applicable. T-test or one-way ANOVA (for continuous variables) and chi-squared test (for categorical variables) were used to compare data between different groups. Non-parametric tests, including Mann-Whitney
$\mathrm{U}$ test and Kruskal-Wallis $\mathrm{H}$ test, were used for data that did not show a normal distribution. Spearman correlation was used to examine the relationship between 10year risk of CVD and associated factors, which including age, diabetes course, complications, plasma glucose, body mass index, blood lipid profile, reproductive factors and treatment regimen. A stepwise multiple linear regression model was performed. The 10-year risk of CVD was the dependent variable. Independent variables were those parameters that were statistically correlated to 10 -year risk of CVD. For all statistical tests, a $P$ value of $<0.05$ was considered to be statistically significant.

\section{Results}

Demographic and clinical characteristics among the three groups $(n=569)$

The demographic and clinical characteristics of the study population and grouping are summarized in Table 1 . The information included age $(49.4 \pm 8.1 \mathrm{y})$, diabetes course $(5.2 \pm 5.3 \mathrm{y}), \quad$ BMI $\left(24.6 \pm 5.1 \mathrm{~kg} / \mathrm{m}^{2}\right)$, waist-to-hip-ratio (0.904 \pm 0.05$), \mathrm{HbA}_{1 \mathrm{c}}(9.6 \pm 2.7 \%)$, FPG $(9.6 \pm 2.9 \mathrm{mmol} / \mathrm{L})$, 2hPG $\quad(13.7 \pm 4.0 \mathrm{mmol} / \mathrm{L}), \quad$ SBP $\quad(134.1 \pm 18.0 \mathrm{mmHg})$, DBP $(83.2 \pm 10.7 \mathrm{mmHg}), \quad$ TC $(181.4 \pm 38.6 \mathrm{mg} / \mathrm{dL})$, TG $(92.6 \pm 81.1 \mathrm{mg} / \mathrm{dL})$, HDL-C $(42.5 \pm 11.6 \mathrm{mg} / \mathrm{dL})$, LDL-C $(92.6 \pm 30.9 \mathrm{mg} / \mathrm{dL})$, Apo A1 $(1.1 \pm 0.19 \mathrm{~g} / \mathrm{L})$ and Apo B $(1.0 \pm 0.30 \mathrm{~g} / \mathrm{L})($ Table 1$)$. Reproductive factors included age at menarche $(15.0 \pm 1.0 \mathrm{y})$, menstrual days $(5.2 \pm 1.3 \mathrm{~d})$ and menstrual cycle $(30.0 \pm 5.4 \mathrm{~d})$ (Table 1$)$. Statistically significant differences were found regarding age, diabetes course, BMI, menstrual days and menstrual cycle among non-menopause, postmenopause $<5$ y and postmenopause $\geq 5$ y subjects. Additionally, compared with postmenopause $<5$ y patients, patients in the postmenopause $\geq 5$ y group had a younger age at menopause, longer duration of time since menopause and shorter total number of reproductive years (i.e., the duration between menarche and menopause) $(P<0.001)$.

\section{Prevalence of the cardiovascular risk factors among all subjects}

Among the T2DM inpatients, the exposure rate of NAFLD, overweight or obesity, hypertension, dyslipidemia and smoking was 58.2, 56.6, 38.1, 36.2 and $0.7 \%$, respectively. The prevalence of hypertension tended to increase with age (Table 2). The usage rate of hypoglycemic agents (including insulin injections and oral medication), antihypertensive agents, lipid modulators and antithrombotic drugs was $88.6,78.3,50.0$ and $27.1 \%$, respectively (Table 1 ). Only $1.2 \%$ of patients achieved all 3 target goals i.e. blood glucose $\left(\mathrm{HbA}_{1 \mathrm{c}}<7 \%\right)$, blood pressure (systolic blood pressure $<130 \mathrm{mmHg}$ and diastolic blood pressure $<80 \mathrm{mmHg}$ ), and blood lipids (total cholesterol $<174 \mathrm{mg} / \mathrm{dL}$ ) [21]. 
Table 1 Demographic and clinical characteristics of the non-menopause, postmenopause $<5$ y and postmenopause $\geq 5$ y patients $(N=569)$

\begin{tabular}{|c|c|c|c|c|c|}
\hline \multirow[t]{2}{*}{ Variable } & \multirow{2}{*}{$\begin{array}{l}\text { Total } \\
(n=569)\end{array}$} & \multicolumn{3}{|l|}{ Group } & \multirow[t]{2}{*}{$P$-value* } \\
\hline & & Non-menopause $(n=172)$ & Postmenopause < 5y $(n=231)$ & Postmenopause $\geq 5 y(n=166)$ & \\
\hline Age, y & $49.4 \pm 8.1$ & $40.7 \pm 7.6^{b, c}$ & $51.2 \pm 4.4^{a, c}$ & $56.0 \pm 2.9^{a, b}$ & $<0.001$ \\
\hline Family history, $\%$ & $276(48.7)$ & $86(50.0)$ & $110(47.8)$ & $80(48.5)$ & 0.910 \\
\hline Diabetes course, y & $5.2 \pm 5.3$ & $3.5 \pm 4.2^{b, c}$ & $5.1 \pm 5.0^{a, c}$ & $7.1 \pm 6.1^{a, b}$ & $<0.001$ \\
\hline $\mathrm{FPG}, \mathrm{mmol} / \mathrm{L}$ & $9.6 \pm 2.9$ & $9.9 \pm 2.9$ & $9.7 \pm 2.7$ & $9.3 \pm 2.9$ & 0.173 \\
\hline $2 \mathrm{hPG}, \mathrm{mmol} / \mathrm{L}$ & $13.7 \pm 4.0$ & $14.0 \pm 3.9$ & $13.4 \pm 3.9$ & $13.9 \pm 4.2$ & 0.281 \\
\hline \multicolumn{6}{|l|}{ C peptide levels, nmol/L } \\
\hline Fasting C peptide & $1.9 \pm 1.0$ & $1.9 \pm 1.2$ & $1.8 \pm 0.9$ & $1.9 \pm 0.9$ & 0.781 \\
\hline 30-min Postprandial C peptide & $2.5 \pm 1.4$ & $2.5 \pm 1.5$ & $2.5 \pm 1.3$ & $2.6 \pm 1.3$ & 0.750 \\
\hline 1-h Postprandial C peptide & $3.4 \pm 2.0$ & $3.3 \pm 2.0$ & $3.3 \pm 2.0$ & $3.5 \pm 1.9$ & 0.482 \\
\hline 2-h Postprandial C peptide & $3.4 \pm 2.5$ & $3.0 \pm 2.5$ & $3.9 \pm 2.5$ & $4.2 \pm 2.5$ & 0.420 \\
\hline 3-h Postprandial C peptide & $3.3 \pm 2.1$ & $3.3 \pm 2.1$ & $3.3 \pm 2.0$ & $3.4 \pm 2.1$ & 0.663 \\
\hline $\mathrm{BMI}, \mathrm{kg} / \mathrm{m}^{2}$ & $24.6 \pm 5.1$ & $25.5 \pm 3.6^{b, c}$ & $24.6 \pm 3.5^{a}$ & $24.7 \pm 3.3^{a}$ & 0.022 \\
\hline$W C, \mathrm{~cm}$ & $85.4 \pm 9.1$ & $85.7 \pm 9.0$ & $84.6 \pm 8.8$ & $86.1 \pm 9.6$ & 0.244 \\
\hline Waist-to-hip-ratio & $0.904 \pm 0.05$ & $0.904 \pm 0.04$ & $0.901 \pm 0.05$ & $0.910 \pm 0.05$ & 0.216 \\
\hline $\mathrm{SBP}, \mathrm{mmHg}$ & $134.1 \pm 18.0$ & $132.9 \pm 17.9$ & $133.8 \pm 17.8$ & $135.9 \pm 19.0$ & 0.276 \\
\hline $\mathrm{DBP}, \mathrm{mmHg}$ & $83.2 \pm 10.7$ & $84.4 \pm 12.1$ & $83.3 \pm 10.1$ & $81.8 \pm 10.7$ & 0.232 \\
\hline $\mathrm{TC}, \mathrm{mg} / \mathrm{dL}$ & $181.4 \pm 38.6$ & $181.4 \pm 38.6$ & $185.3 \pm 38.6$ & $181.4 \pm 42.5$ & 0.567 \\
\hline $\mathrm{TG}, \mathrm{mg} / \mathrm{dL}$ & $92.6 \pm 80.1$ & $96.5 \pm 88.8$ & $92.6 \pm 77.2$ & $88.8 \pm 77.2$ & 0.672 \\
\hline $\mathrm{HDL}-\mathrm{C}, \mathrm{mg} / \mathrm{dL}$ & $42.5 \pm 11.6$ & $42.5 \pm 11.6$ & $42.5 \pm 11.6$ & $42.5 \pm 11.6$ & 0.304 \\
\hline $\mathrm{LDL}-\mathrm{C}, \mathrm{mg} / \mathrm{dL}$ & $92.6 \pm 30.9$ & $92.6 \pm 27.0$ & $96.5 \pm 34.7$ & $92.6 \pm 30.9$ & 0.742 \\
\hline Apo A1, g/L & $1.1 \pm 0.19$ & $1.1 \pm 0.15$ & $1.1 \pm 0.22$ & $1.1 \pm 0.18$ & 0.632 \\
\hline Apo B, g/L & $1.0 \pm 0.30$ & $1.0 \pm 0.27$ & $1.0 \pm 0.21$ & $1.0 \pm 0.42$ & 0.376 \\
\hline $\mathrm{HbA}_{1 c} \%$ & $9.6 \pm 2.7$ & $9.8 \pm 2.3$ & $9.6 \pm 3.2$ & $9.4 \pm 2.4$ & 0.149 \\
\hline \multicolumn{6}{|l|}{ Complications, \% } \\
\hline Retinopathy & $33(5.8)$ & $8(4.7)$ & $13(5.6)$ & $12(7.2)$ & 0.592 \\
\hline Neuropathy & $122(21.4)$ & $25(14.5)$ & $47(20.3)$ & $50(30.1)$ & 0.002 \\
\hline Diabetic foot & $5(0.9)$ & $0(0.0)$ & $2(0.9)$ & $3(1.8)$ & 0.205 \\
\hline Kidney disease & $36(6.3)$ & $10(5.8)$ & $18(7.8)$ & $8(4.8)$ & 0.461 \\
\hline Ketoacidosis & $73(12.8)$ & $35(20.3)$ & $30(13.0)$ & $8(4.8)$ & $<0.001$ \\
\hline Hypoglycemic agents, \% & $503(88.6)$ & $150(87.2)$ & 207 (89.6) & $146(88.5)$ & 0.755 \\
\hline Insulin injections & $358(62.9)$ & 118 (68.6) & $139(60.2)$ & $101(60.8)$ & 0.179 \\
\hline Metformin & $427(75.0)$ & $133(77.3)$ & $170(73.6)$ & $124(74.7)$ & 0.688 \\
\hline Sulfanylureas & $120(21.1)$ & $32(18.6)$ & $54(23.4)$ & $34(20.5)$ & 0.496 \\
\hline Glinides & $69(12.1)$ & $10(5.8)$ & $28(12.1)$ & $30(20.1)$ & $<0.001$ \\
\hline aglucosidase inhibitors & $375(65.9)$ & $113(65.7)$ & $152(65.8)$ & $110(66.3)$ & 0.993 \\
\hline Pioglitazone & $37(6.5)$ & $13(7.6)$ & $16(6.9)$ & $8(4.8)$ & 0.561 \\
\hline Insulin plus oral medication & $314(55.2)$ & $94(54.7)$ & $133(57.6)$ & $87(52.4)$ & 0.706 \\
\hline \multicolumn{6}{|l|}{ Treatment regimens, \% } \\
\hline Antihypertensive agents & $170(78.3)$ & $29(13.4)$ & $82(82.8)$ & $59(78.7)$ & 0.123 \\
\hline Lipid modulators & $103(50.0)$ & $25(39.7)$ & $49(55.7)$ & $29(52.7)$ & 0.137 \\
\hline Antithrombotic drugs & $156(27.1)$ & $24(14.0)$ & 79 (34.2) & $53(31.9)$ & $<0.001$ \\
\hline Alcohol intake, \% & $2(0.4)$ & 0 & $1(0.4)$ & $1(0.6)$ & 0.622 \\
\hline
\end{tabular}


Table 1 Demographic and clinical characteristics of the non-menopause, postmenopause $<5$ y and postmenopause $\geq 5$ y patients $(N=569)$ (Continued)

\begin{tabular}{|c|c|c|c|c|c|}
\hline \multirow[t]{2}{*}{ Variable } & \multirow{2}{*}{$\begin{array}{l}\text { Total } \\
(n=569)\end{array}$} & \multicolumn{3}{|l|}{ Group } & \multirow[t]{2}{*}{$P$-value } \\
\hline & & Non-menopause $(n=172)$ & Postmenopause $<5 y(n=231)$ & Postmenopause $\geq 5 y(n=166)$ & \\
\hline Hypoglycemia, \% & $39(6.9)$ & $5(2.9)$ & $22(9.5)$ & $12(7.2)$ & 0.033 \\
\hline \multicolumn{6}{|l|}{ Reproductive factors } \\
\hline Age at menarche, $y$ & $15.0 \pm 1.0$ & $14.9 \pm 1.1$ & $15.1 \pm 0.9$ & $15.1 \pm 1.1$ & 0.140 \\
\hline Menstrual days, day & $5.2 \pm 1.3$ & $5.4 \pm 1.3^{c}$ & $5.1 \pm 1.3$ & $5.0 \pm 1.3^{a}$ & 0.048 \\
\hline Menstrual cycle, day & $30.0 \pm 5.4$ & $31.3 \pm 8.5^{b, c}$ & $29.6 \pm 3.6^{a}$ & $29.3 \pm 1.9^{a}$ & 0.010 \\
\hline Reproductive years, y & - & - & $34.5 \pm 4.0$ & $32.8 \pm 3.7$ & $<0.001$ \\
\hline Menopause age, y & & & $49.6 \pm 3.9$ & $47.9 \pm 3.5$ & $<0.001$ \\
\hline Time since menopause, y & - & - & $1.66 \pm 1.58$ & $8.2 \pm 2.7$ & $<0.001$ \\
\hline
\end{tabular}

${ }^{a}$ Compared with the non-menopausal group, $P<0.05$;

${ }^{b}$ Compared with the postmenopause $<5$ y group, $P<0.05$;

${ }^{c}$ Compared with the postmenopause $\geq 5$ y group, $P<0.05$;

*Compared among groups

\section{Framingham risk score and 10-year risk of CVD among the three groups}

The Framingham Risk Score was $(10.3 \pm 4.5)$, and the 10 -year risk of CVD was $(1.6 \pm 1.5 \%)$, and both indicator values increased along with the age $(P<0.001)$ (Table 3$)$.

\section{Related factors associated with 10-year risk of CVD among all patients}

Among all subjects, the 10-year risk of CVD was a dependent variable, in addition to age, TC, SBP, smoking, diabetes course, complications, FPG, 2hPG, BMI, waist-to-hip-ratio, TG, LDL-C, Apo $A_{1}$, Apo $B$ and menopausal state $($ no $=0$, yes $=1)$, while the treatment regimens were independent variables, which were performed in a stepwise multiple linear regression model. The results are shown in Table 4. The 10-year risk of CVD was found to be positively correlated with menopausal state (no $=0$, yes $=1$ ), LDL-C, FPG and waist-tohip-ratio $(\beta=0.275,0.212,0.093,-0.078$, respectively, $P<0.05)$, which may explain the variance of $14.3 \%$. Menopause, LDL-C, FPG and waist-to-hip-ratio were found to be independent risk factors for the 10-year risk of CVD.

\section{Risk factors associated with 10-year risk of CVD in postmenopausal patients}

In the postmenopausal group, 10-year risk of CVD was as dependent variable. Except for age, TC, SBP and smoking, the independent variables were diabetes course, complications, FPG, 2hPG, BMI, waist-to-hip-ratio, TG, LDL-C, Apo $\mathrm{A}_{1}$, Apo $\mathrm{B}$, menopause age, time since menopause, total reproductive years and treatment regimens. LDL-C $(\beta=0.227, P<0.001)$, FPG $(\beta=0.139$, $P=0.003)$ and time since menopause $(\beta=0.230, P<$ 0.001) were found to be associated with CVD, which may explain the variance of $14.6 \%$ (Table 5 ).

\section{Discussion}

The findings of the present study indicate that the incidence of dyslipidemia, hypertension, overweight or obesity and NAFLD is high. All these indicators are considered to be conventional cardiovascular risk factors. The association between these factors and cardiovascular disease is well known [21, 24-26]. The prevalence of dyslipidemia, hypertension, overweight or obesity and NAFLD in diabetic patients was found to be 36.2, 38.1, 56.6 and 58.2\%, respectively, in the current study, which is higher than the

Table 2 The distribution of cardiovascular risk factors among the different groups (\%)

\begin{tabular}{lllllll}
\hline Group & $\mathrm{n}$ & Hypertension & Dyslipidemia & NAFLD & Overweight or obesity & Smoking \\
\hline Non-menopause & 172 & $43(25.0)$ & $63(36.6)$ & $105(61.0)$ & $109(63.4)$ & $1(0.6)$ \\
Postmenopause<5y & 231 & $99(42.9)$ & $88(38.1)$ & $131(56.7)$ & $123(53.2)$ & $3(1.3)$ \\
Postmenopause $25 y$ & 166 & $75(45.2)$ & $55(33.1)$ & $95(57.2)$ & $90(54.2)$ & 0 \\
$x^{2}$ & & 18.254 & 1.049 & 0.848 & 7.343 & 2.386 \\
$P$ & & $<0.001$ & 0.592 & 0.655 & 0.119 & 0.303 \\
\hline
\end{tabular}


Table 3 Framingham Risk Score and 10-year risk of CVD

\begin{tabular}{llll}
\hline Group & $\mathrm{n}$ & Framingham Risk Score & 10 -year risk of CVD (\%) \\
\hline Non-menopause & 172 & $6.3 \pm 4.5^{\mathrm{b}, \mathrm{c}}$ & $1.0 \pm 0.4^{\mathrm{b}, \mathrm{c}}$ \\
Postmenopause $<5 \mathrm{y}$ & 231 & $11.3 \pm 3.4^{\mathrm{a}, \mathrm{c}}$ & $1.7 \pm 1.3^{\mathrm{a}, \mathrm{c}}$ \\
Postmenopause $\geq 5 \mathrm{y}$ & 166 & $12.9 \pm 2.5^{\mathrm{a}, \mathrm{b}}$ & $2.1 \pm 2.0^{\mathrm{a}, \mathrm{b}}$ \\
$F$ & & 163.357 & 27.726 \\
$P^{*}$ & & $<0.001$ & $<0.001$ \\
\hline
\end{tabular}

${ }^{a}$ Compared with the non-menopausal group, $P<0.05$;

${ }^{b}$ Compared with the postmenopause $<5$ y group, $P<0.05$;

${ }^{c}$ Compared with the postmenopause $\geq 5$ y group, $P<0.05$;

"Compared among groups

rates reported of Ma et al. [27], Bachir Cherif et al. [28], Echouffo-Tcheugui et al. [29] and Younossi et al. [30]. The total prevalence in their studies were found to be 13.1, 31.6, 44.5 and $25.24 \%$, respectively. The explanation for these differences may be due to differences among sample populations. In our study, subjects were recruited from among inpatients who had suffered from diabetes under critical conditions. The participants of the other studies were selected from a community dwelling or were outpatients, and most of them were healthy. In the current study, except for hypoglycemic agents, the usage rate of antihypertensive agents, lipid modulators and antithrombotic drugs was low. According to the guidelines for T2DM, health care professionals should promptly detect T2DM patients with hypertension, dyslipidemia and NAFLD, and provide early treatment measures, such as antihypertensive agents, lipid modulators and aspirin [21]. However, the treatment status of these Chinese T2DM inpatients was not ideal. In addition, the target goals for the control of blood glucose, blood pressure and blood lipids was only $1.2 \%$, which is significantly lower than the $5.6 \%$ reported among type 2 diabetic outpatients [31]. Thus, achieving adequate control of risk factors for cardiovascular disease in patients with type 2 diabetes remains a clinical challenge [31]. For diabetic patients, complications may include dyslipidemia, hypertension, overweight or obesity, NAFLD. Therefore, healthcare professionals should not only focus on helping patients monitor their plasma glucose levels, but also intervene to achieve control of blood pressure and serum lipid.

We found that a higher risk of CVD was observed among diabetic patients who have experienced menopause, compared with non-menopausal women. The related factors are LDL-C and FPG levels. Two studies have shown that menopause has a marked effect on the circulation levels of lipids and lipoproteins, with an especially significant increase in LDL-C levels $[32,33]$. Previous studies have examined the association between FPG, $2 \mathrm{hPG}$ and CVD risk in a community $[18,34,35]$. These studies have reported significant results, which are consistent with our findings. Shen et al. also indicate that postmenopausal women show significant association with worse glycemic control, including FPG levels, which is independently associated with 10-year cardiovascular risk [36, 37]. Additionally, diabetes is associated with chronic inflammation, which is characterized by the release of excess pro-inflammatory cytokines, abrupt levels of acute-phase proteins, and other mediators, which are integral to the severity of cardiovascular disorders [38-40]. Menopause complicated with diabetes is an independent predictor of cardiovascular disease. Our study shows that the waist-to-hip-ratio is a protective factor for 10-year risk of CVD. In a study conducted on five hundred postmenopausal women study, truncal obesity with a waist-hip ratio $>0.8$ was found in $68 \%$ of females, which does not indicate the association between waist-to-hip ratio and 10-year risk of CVD [41]. This is

Table 4 Stepwise multiple linear regression for 10-year risk of CVD and related factors among all subjects $(N=569)$

\begin{tabular}{lllll}
\hline Model & Unstandardized coefficients & Standardized coefficients & $t$ & $P$-value \\
& $B$ & $\beta$ & 0.275 & 7.043 \\
\hline Menopause or not & 0.868 & 0.212 & 5.379 & $<0.001$ \\
LDL-C & 0.387 & 0.093 & 2.364 & 0.001 \\
FPG & 0.046 & 0.078 & 1.993 & 0.018 \\
Waist-to-hip-ratio & 2.238 & - & -3.104 & 0.047 \\
Constant & -3.249 & & 0.002 \\
\hline
\end{tabular}

$R^{2}=0.143$ 
Table 5 Stepwise multiple linear regression for 10-year risk of CVD and related factors in postmenopausal patients $(n=397)$

\begin{tabular}{|c|c|c|c|c|}
\hline Model & $\begin{array}{l}\text { Unstandardized coefficients } \\
B\end{array}$ & $\begin{array}{l}\text { Standardized coefficients } \\
\beta\end{array}$ & $t$ & $P$-value \\
\hline $\mathrm{LDL}-\mathrm{C}$ & 0.449 & 0.227 & 4.783 & $<0.001$ \\
\hline FPG & 0.078 & 0.139 & 2.947 & 0.003 \\
\hline Time since menopause & 0.099 & 0.230 & 4.672 & $<0.001$ \\
\hline Constant & -4.568 & - & -4.069 & $<0.001$ \\
\hline
\end{tabular}

$R^{2}=0.146$

an urgent matter for healthcare providers to assist these patients in establishing a good lifestyle, in order to maintain a proper waist-to-hip ratio.

Furthermore, as the period of time since menopause increases, the CVD risk also increases. In a Chinese population study, compared to women who had been menopausal for less than 1 year, those with elapsed time since menopause of 2-3 years had higher coronary heart disease prevalence, and higher TG levels [42]. Cho et al. also determined that 10 to 14 years after menopause, postmenopausal women show an increased risk of high TG [43]. Additionally, time since menopause may related to some conventional CVD risk factors, such as metabolic syndrome or obesity $[40,43]$. But a review has shown that there is no meaningful relationship that has emerged between time since menopause and CVD risk factors [44]. Further, a study of the relationship between time since menopause and CVD risk or relevant diseases is needed to explain the biological mechanisms.

This study has several limitations. First, although this is the first study to report that cardiovascular risk factors of menopausal women with type 2 diabetes mellitus, the study used a hospital-based cohort of a Chinese population, indicating that the study sample was from a single hospital. We cannot assume that our findings can be generalize to other groups. Second, the study population was hospitalized patients, which may have introduced a selection bias. In addition, there was also a memory bias in the study, especially when we asked some questions about reproductive factors, such as menstrual days, menstrual cycle, menopausal age, complications, and treatment regimen, subjects had to recall what had happened in the past, which is not the best method. Third, the lack of a non-diabetic agematched control group was also a limitation of this study. Fourth, due to the observational nature of the study, the mechanisms proposed to explain the association between higher risk of CVD, menopausal status and FPG are merely speculative. Indeed, no tests of sex hormones have been performed. Finally, an analysis of the difference in autoantibody positivity between the non-menopause group and the menopause groups was not conducted, which is a shortcoming of this study.

\section{Conclusions}

In conclusion, among women with type 2 diabetes mellitus in China, the prevalence of cardiovascular risk factors are high. Although there is overwhelming evidence to indicate that achieving adequate control of blood pressure and lipids can significantly delay or prevent the onset of CVD, successful accomplishment of recommended therapeutic goals is a huge challenge. In diabetic females, except for menopausal state and time since menopause being uncontrollable factors, LDL-C, FPG and waist-to-hip ratio were found to be controllable factors. The clinical management of diabetes needs change. In addition to monitoring plasma glucose, interventions to improve blood pressure, serum lipids and lifestyle are needed. These women are currently too young to have experienced CVD events, therefore, the continued follow-up of these women needs to be conducted.

\section{Abbreviations}

2hPG: 2 h postprandial glucose; Apo A1: Apolipoprotein A1; Apo B: Apolipoprotein B; BMI: Body mass index; CVD: Cardiovascular disease; DBP: Diastolic blood pressure; FPG: Fasting plasma glucose; FRS: Framingham risk score; $\mathrm{HbA}_{1}$ : Hemoglobin $\mathrm{A}_{1}$; $\mathrm{HDL}-\mathrm{C}$ : High-density lipoprotein cholesterol; LDC-C: Low-density lipoprotein cholesterol; NAFLD: Nonalcoholic fatty liver disease; SBP: Systolic blood pressure; T2DM: Type 2 diabetes mellitus; TC: Total cholesterol; TG: Triglycerides; WC: Waist circumference

\section{Acknowledgements}

The authors thank the subjects who participated in this study, without their kind cooperation, this study would not have been possible. We also acknowledge researchers at The First People's Hospital of Changzhou for participating in this study. The authors thank Jumei Li, Weibin Zhu and Huajuan Chen for their assistance with data collection and management.

\section{Authors' contributions}

$\mathrm{HH}$, and $\mathrm{XY}$ performed the statistical analyses, interpreted the data and drafted the manuscript. $\mathrm{CH}$ and JY contributed to the statistical analyses, interpretation of the data and revised the manuscript critically before submission. All authors read and approved the final manuscript.

\section{Funding}

This study was not funded by any one.

\section{Availability of data and materials}

The datasets used and/or analyzed during the current study are available from the corresponding author on reasonable request.

\section{Ethics approval and consent to participate}

This study was approved by the Ethics Board Committee of The First people's Hospital of Changzhou. The personal information and medical records of each patient were strictly protected. When the patients were 
admitted to the hospital, the doctor signed a treatment consent form with them and asked if they agreed to participate in our study. The signed documents were kept with the documentation of each patient. When they were discharged from hospital, the cases were filed, resulting in written consent not needed again. However, verbal informed consent was obtained from all participants in our study.

\section{Consent for publication}

Not applicable.

\section{Competing interests}

The authors declare that they have no competing interests.

\section{Received: 29 April 2019 Accepted: 13 September 2019} Published online: 11 October 2019

\section{References}

1. Yang L, Lin L, Kartsonaki C, Guo Y, Chen Y, Bian Z, Xie K, Jin D, Li L, LV J, Chen Z; China Kadoorie Biobank Study Collaborative Group. Menopause characteristics, total Reproductive years, and risk of cardiovascular disease among Chinese women. Circ Cardiovasc Qual Outcomes. 2017;10(11): e004235.

2. Yang G, Wang $Y$, Zeng $Y$, Gao GF, Liang X, Zhou $M$, Wan X, Yu S, Jiang Y Naghavi M, Vos T, Wang H, Lopez AD, Murray CJ. Rapid health transition in China, 1990-2010: findings from the global burden of disease study 2010. Lancet. 2013;381:1987-2015.

3. Lisabeth $\mathrm{L}$, Bushnell C. Stroke risk in women: the role of menopause and hormone therapy. Lancet Neurol. 2012;11:82-91.

4. He L, Tang X, Li N, Wu YQ, Wang JW, Li JR, Zhang ZX, Dou HD, Liu JJ, Yu LP Xu HT, Zhang JG, Hu YH. Menopause with cardiovascular disease and its risk factors among rural Chinese women in Beijing: a population-based study. Maturitas. 2012;72(2):132-8.

5. Bjorkelund C, Lissner L, Andersson S, Lapidus L, Bengtsson C. Reproductive history in relation to relative weight and fat distribution. Int J Obes Relat Metab Disord. 1996;20(3):213-9.

6. de Kleijn MJ, van der Schouw YT, van der Graaf Y. Reproductive history and cardiovascular disease risk in postmenopausal women: a review of the literature. Maturitas. 1999:33:7-36.

7. Polak JF, Szklo M, Kronmal RA, Burke GL, Shea S, Zavodni AE, O'Leary DH. The value of carotid artery plaque and intima-media thickness for incident cardiovascular disease: the multi-ethnic study of atherosclerosis. J Am Heart Assoc. 2013;2(2):e87

8. Prisant LM, Zemel PC, Nichols FT, Zemel MB, Sowers JR, Carr AA, Thompson WO, Bond MG. Carotid plaque associations among hypertensive patients. Arch Intern Med. 1993;153(4):501-6.

9. Chakrabarti S, Morton JS, Davidge ST. Mechanisms of estrogen effects on the endothelium: an overview. Can J Cardiol. 2014;30(7):705-12.

10. Kanaya AM, Grady D, Barrett-Connor E. Explaining the sex difference in coronary heart disease mortality among patients with type 2 diabetes mellitus. A meta-analysis. Arch Intern Med. 2002;162(15):1737-45.

11. Kannel WB, Wilson WP. Risk factors that attenuate the female coronary disease advantage. Arch Intern Med. 1995;155(1):57-61.

12. Meyer MR, Clegg DJ, Prossnitz ER, Barton M. Obesity, insulin resistance and diabetes: sex differences and role of oestrogen receptors. Atca physiol (Oxf). 2011;203(1):259-69.

13. Chakrabarti S, Davidge ST. High glucose-induced oxidative stress alters estrogen effects on ERa and ER $\beta$ in human endothelial cells: reversal by AMPK activator. J Steroid Biochem Mol Biol. 2009:117:99-106.

14. Ishibashi Y, Matsui T, Ueda S, Fukami K, Yamagishi S. Role of advanced glycation end products (AGE) in thrombogenic abnormalities in diabetes. Curr Neurovasc Res. 2006;3(1):73-7.

15. Yang L, Li L, Millwood IY, Peters SAE, Chen Y, Guo Y, Bian Z, Chen X, Chen L, Feng S, Lv S, Pang Z, Woodward M, Chen Z. China Kadoorie biobank study collaborative group (members listed in the acknowledgement section): age at menarche and risk of major cardiovascular diseases: evidence of birth cohort effects from a prospective study of 300,000 Chinese women. Int Cardiol. 2017:227:497-502

16. de Kleijn MJ, van der Schouw YT, Verbeek AL, Peeters PH, Banga JD, van der Graaf Y. Endogenous estrogen exposure and cardiovascular mortality risk in postmenopausal women. Am J Epidemiol. 2002;155:339-45.
17. Wu XY, Cai H, Kallianpur A, Gao YT, Yang G, Chow WH, Li HL, Zheng W, Shu $X O$. Age at menarche and natural menopause and number of reproductive years in association with mortality: results from a median follow up of 11.2 years among 31,955 naturally menopausal Chinese women. PLoS One. 2014;9:e103673.

18. Wang A, Liu X, Xu J, Han X, Su Z, Chen S, Zhang N, Wu S, Wang Y, Wang Y. Visit-to-visit variability of fasting plasma glucose and the risk of cardiovascular disease and all-cause mortality in the general population. J Am Heart Assoc. 2017:6(12):e006757.

19. Gallagher LG, Davis LB, Ray RM, Psaty BM, Gao DL, Checkoway H, Thomas DB. Reproductive history and mortality from cardiovascular disease among women textile workers in Shanghai. China Int J Epidemiol. 2011;40:1510-8.

20. Yan L, Xu MT, Yuan L, Chen B, Xu ZR, Guo QH, Li Q, Duan Y, Huang Fu J, Wang YJ, Zhang M, Luo ZJ, Zhao WG, Wang YM, Yuan ZF, Wang WQ, Wang PH, Ran XW, Wang YJ, Yang HZ, Gao L, Chen WQ, Ning G. Prevalence of dyslipidemia and its control in type 2 diabetes: a multicenter study in endocrinology clinics of China. J Clin Lipidol. 2016:10(1):150-60.

21. China Society of Diabetes. China guideline for type 2 diabetes (2017). Chin Pract Int Med. 2018;38(4):292-343.

22. Moreno-Del Castillo MC, Sanchez-Rodriguez A, Hernandez-Buen Abad J, Aguirre-Valadez J, Ruiz I, Garcia-Buen Abad R, Oliva K, Piccolo J, De Icaza-Del Rio E, Mena-Ramirez JR, Mendizabal-Rodriguez ME, Atkinson-Ginsburg NM, Salazar-Segovia J, Ríos-Zertuche CA. Importance of evaluating cardiovascular risk and hepatic fibrosis in patients with NewlyDiagnosed nonalcoholic fatty liver disease. Clin Gastroenterol Hepatol. 2019;17(5):997-9.

23. Sohn C, Kim J, Bae W. The Framingham risk score, diet, and inflammatory markers in Korean men with metabolic syndrome. Nutr Res Pract. 2012;6(3): 246-53.

24. Asgeirsdottir TL, Olafsdottir T, Ragnarsdottir DO. Business cycles, hypertension and cardiovascular disease: evidence from the Icelandic economic collapse. Blood Press. 2014;23(4):213-21.

25. Teramoto T, Sasaki J, Ishibashi S, Birou S, Daida H, Dohi S, Egusa G, Hiro T, Hirobe K, lida M, Kihara S, Kinoshita M, Maruyama C, Ohta T, Okamura T, Yamashita S, Yokode M, Yokote K. Absolute risk of cardiovascular disease and lipid management targets. J Atheroscler Thromb. 2013;20(9):689-97.

26. Fargion S, Porzio M, Fracanzani AL. Nonalcoholic fatty liver disease and vascular disease: state-of-the-art. World J Gastroenterol. 2014;20(37):13306-24.

27. Ma D, Sakai H, Wakabayashi C, Kwon JS, Lee Y, Liu S, Wan Q, Sasao K, Ito K, Nishihara K, Wang P. The prevalence and risk factor control associated with noncommunicable diseases in China, Japan, and Korea. J Epidemiol. 2017; 27(12):568-73.

28. Bachir Cherif A, Bouamra A, Taleb A, Nedjar R, Bouraghda A, Hamida F, Temmar M, Bouafia MT. Differences in prevalence, treatment and control rates of hypertension between male and female in the area of Blida (Algeria). Ann Cardiol Angeiol. 2017:66(3):123-9.

29. Echouffo-Tcheugui JB, Short MI, Xanthakis V, Field P, Sponholtz TR, Larson MG, Vasan RS. Natural history of obesity subphenotypes: dynamic changes over two decades and prognosis in the Framingham heart study. J Clin Endocrinol Metab. 2019:104(3):738-52.

30. Younossi ZM, Koenig AB, Abdelatif D, Fazel Y, Henry L, Wymer M. Global epidemiology of nonalcoholic fatty liver disease-meta-analytic assessment of prevalence, incidence, and outcomes. Hepatology. 2016;64(1):73-84

31. Ji L, Hu D, Pan C, Weng J, Huo Y, Ma C, Mu Y, Hao C, Ji Q, Ran X, Su B, Zhuo H, Fox KA, Weber M, Zhang D. CCMR Advisory Board; CCMR-3B STUDY Investigators. Primacy of the $3 \mathrm{~B}$ approach to control risk factors for cardiovascular disease in type 2 diabetes patients. Am J Med. 2013;126(10):925.e11-22.

32. de Aloysio D, Gambacciani M, Meschia M, Pansini F, Bacchi Modena A, Bolis PF, Massobrio M, Maiocchi G, Peruzzi E. The effect of menopause on blood lipid and lipoprotein levels. The Icarus Study Group. Atherosclerosis. 1999:147(1):147-53.

33. Razmjou S, Abdulnour J, Bastard JP, Fellahi S, Doucet É, Brochu M, Lavoie JM, Rabasa-Lhoret R, Prud'homme D. Body composition, cardiometabolic risk factors, physical activity, and inflammatory markers in premenopausal women after a 10-year follow-up: a MONET study. Menopause. 2018;25(1): 89-97.

34. Ren $Y$, Zhang M, Liu Y, Sun X, Wang B, Zhao Y, Liu D, Liu X, Zhang D, Liu F, Cheng C, Liu L, Chen X, Zhou Q, Hu D. Association of menopause and type 2 diabetes mellitus. Menopause. 2019:26(3):325-30.

35. Ikeda N, lijima R, Hara H, Moroi M, Nakamura M, Sugi K. Glycated hemoglobin is associated with the complexity of coronary artery disease, even in non-diabetic adults. J Atheroscler Thromb. 2012;19(12):1066-72. 
36. Shen C, Wen J, Pan X, Su J, Du W, Pan E, Zhang Q, Zhang N, Sheng H, Liu C, Wang $\mathrm{H}$, Wu M, Qin Y. Age at menarche and age at natural menopause as predictors of glycemic control in type 2 diabetic patients. J Diabetes Complicat. 2018;32(7):623-9.

37. Ama Moor VJ, Nansseu JR, Nouaga ME, Noubiap JJ, Nguetsa GD, Tchanana G, Ketcha A, Fokom-Domgue J. Assessment of the 10-year risk of cardiovascular events among a group of sub-Saharan African postmenopausal women. Cardiol J. 2016;23(2):123-31.

38. Pandey A, Chawla S, Guchhait P. Type-2 diabetes: current understanding and future perspectives. IUBMB Life. 2015;67(7):506-13.

39. Paneni F, Beckman JA, Creager MA, Cosentino F. Diabetes and vascular disease: pathophysiology, clinical consequences, and medical therapy: part I. Eur Heart J. 2013;34:2436-43.

40. Wang Q, Ferreira DLS, Nelson SM, Sattar N, Ala-Korpela M, Lawlor DA. Metabolic characterization of menopause: cross-sectional and longitudinal evidence. BMC Med. 2018;16(1):17.

41. Tandon VR, Mahajan A, Sharma S, Sharma A. Prevalence of cardiovascular risk factors in postmenopausal women: a rural study. J Midlife Health. 2010;1(1):26-9.

42. Stöckl D, Peters A, Thorand B, Heier M, Koenig W, Seissler J, Thiery J, Rathmann W, Meisinger C. Reproductive factors, intima media thickness and carotid plaques in a cross-sectional study of postmenopausal women enrolled in the population-based KORA F4 study. BMC Womens Health. 2014;14:17.

43. Cho GJ, Lee JH, Park HT, Shin JH, Hong SC, Kim T, Hur JY, Lee KW, Park YK, Kim SH. Postmenopausal status according to years since menopause as an independent risk factor for the metabolic syndrome. Menopause. 2008;15: 524-9.

44. Fioretti F, Tavani A, Gallus S, Franceschi S, La Vecchia C. Menopause and risk of non-fatal acute myocardial infarction: an Italian case-control study and a review of the literature. Hum Reprod. 2000;15:599-603.

\section{Publisher's Note}

Springer Nature remains neutral with regard to jurisdictional claims in published maps and institutional affiliations.

Ready to submit your research? Choose BMC and benefit from:

- fast, convenient online submission

- thorough peer review by experienced researchers in your field

- rapid publication on acceptance

- support for research data, including large and complex data types

- gold Open Access which fosters wider collaboration and increased citations

- maximum visibility for your research: over $100 \mathrm{M}$ website views per year

At $\mathrm{BMC}$, research is always in progress.

Learn more biomedcentral.com/submissions 